\title{
GERAKAN ISLAM POLITIK DAN PROYEK HISTORIS PENEGAKAN ISLAMISME DI INDONESIA
}

\author{
Rendy Adiwilaga \\ Fakultas Ilmu Sosial dan Ilmu Politik Universitas Bale Bandung, \\ Kabupaten Bandung, Indonesia \\ E-mail: rendyadiwilaga@gmail.com
}

\begin{abstract}
ABSTRAK
Pasca kebangkitan reformasi, perjuangan Islamisme bertransformasi menjadi sebuah gerakan sosial sebagai sebuah representasi masyarakat modern. Tulisan ini hendak memaparkan temuan historis serta mengkaji, bagaimana gerakan Islamisme di Indonesia berdinamika mulai dari awal kebangkitannya hingga upaya nya menyesuaikan diri dengan perkembangan zaman. Tanpa melibatkan arus radikal lebih jauh, tulisan ini hanya mencoba menggali gerakan Islamisme mulai dari Sarikat Islam, Darul Islam, Masyumi, hingga FPI sebagai representasi gerakan Islamisme kontemporer dengan menggunakan pendekatan fenomenologis.
\end{abstract}

Kata kunci: Islam Politik, Islamisme, Gerakan Islam

\section{POLITICAL ISLAM MOVEMENT AND HISTORICAL PROJECT OF ISLAMISM ENFORCEMENT IN INDONESIA}

\begin{abstract}
After Post-resurrection reform, the struggling of Islamism was transformed into a social movement as a representation of modern society. This paper is about to expose the historical findings and examine how the movement of Islamism in Indonesia showing some dynamics act start from the beginning its rise to its efforts to adjust to the times. Without involving radical currents further, this article is only trying to dig the Islamism Movement start from Sarikat Islam, Darul Islam, Masjumi, until FPI as a representation of contemporary Islamism movement using the phenomenological approach.
\end{abstract}

Key words: Islam of Politics, Islamism, Islam Movement.

\section{PENDAHULUAN}

Islam dan perjalanan panjang sejarah Indonesia, pada hakikatnya merupakan dua sisi pedang yang sulit terpisahkan. Kelahiran Indonesia sendiri tidak luput dari peran serta tokoh-tokoh serta organisasi-organisasi Islam besar di Indonesia, mulai dari para pedagang Arab, Gujarat, dan Cina, kerajaan besar Islam mulai dari Aceh hingga Ternate, tokoh Padri di Sumatera Barat, hingga organisasi besar Islam awal abad ke 20 seperti Muhammadiyah, Sarikat Islam, Persis, hingga Nahdhatul Ulama (NU). Semua memiliki peran khusus dalam mengisi proses perjuangan bangsa menuju kemerdekaan. Pun halnya dengan internalisasi Islam itu sendiri. Terbukanya masyarakat pelabuhan serta pedesaan terhadap ajaran Islam pada akhirnya memudahkan Islam itu sendiri menjadi kekuatan baru dengan keunggulan kuantitasnya pada awal abad ke 20.

Islamisme, yang menggambarkan konsep Islam tidak hanya sebagai konsep Ilahiah melainkan juga konsep yang utuh dalam sendi politik dan kenegaraan, sejatinya mulai muncul pada awal abad ke 17. Kemajuan Barat yang disusul dengan kemunduran dunia Islam, selain memberikan pukulan keras, pada akhirnya juga menjadi bahan evaluasi bagi para pemikir Islam, untuk melakukan perubahan dan perbaikan di berbagai sendi. Abad ke-18 menjadi titik tolak pergerakan Islam untuk melakukan perubahan. Berdasarkan catatan Fealy dan Bubalo, gerakan pemikiran Islam dipelopori oleh Muhammad bin Abdul Wahab (17031787) di Arabia Tengah, disusul trio Jamaludin Al-Afghani (1839-1897), Muhammad Abduh (1849-1905), dan Rasyid Ridha (1865-1935) pada abad 19 dan 20. (Fealy \& Bubalo, 2007: 30). Gerakan pemikiran tersebut pada akhirnya 
menginspirasi banyak cendekiawan dan mubaligh nusantara di awal abad ke 20 .

Menurut Bachtiar (2013), Kebangkitan Islam, khususnya Islam Politik sebagai kekuatan baru juga ditunjukkan dari maneuver Sarikat Islam pimpinan Tjokroaminoto sebagai pemantik awal bangkit dan lepasnya Islam dari stereotip umum sebagai hal yang hanya mengurusi "perkara ibadah dan moral sahaja". Popularitas gerakan Islam secara politik bahkan tidak luntur sampai disana. Kelahiran Masyumi dan kemenangannya (bersama NU) sebagai 4 partai pemenang pemilu tahun 1955 , kejayaan Hizbullah DI/TII tahun 1949-1962 dengan ribuan tentaranya dalam penegakan Negara Islam Indonesia (NII), hingga dewasa ini kebangkitan Front Pembela Islam (FPI) ${ }^{1}$ sebagai pioneer gerakan keislaman kontemporer, tidak bisa menampik perihal kenyataan bahwa isu Gerakan Islam maupun Islam Politik, hingga detik ini masih laris dikonsumsi masyarakat baik dari segi kulit saja maupun secara substansial sebagai akibat dari anggapan tentang kegagalan sekulerisme dalam mengelola negara dan masyarakat.

Tulisan ini kemudian hendak mengkaji bagaimana perjalanan transformasi kekuatan Islam di Indonesia yang sebelumnya berwujud gerakan kemasyarakatan yang agitatif dan propagandis pada masa pra dan pasca kemerdekaan, kemudian menjadi gerakan kajian keagamaan yang pasif, hingga kemudian kembali menjadi sebuah gerakan kemasyarakatan yang aktif memperjuangkan Islamisme sebagai refleksi modernitas masyarakat dewasa ini. Permasalahan tersebut juga diharapkan akan menjawab anggapan dari Sztompka (1993: 239) serta Eyerman \& Jamison (1991: 53) bahwa gerakan sosial (maupun politik) adalah bagian sentral dari modernitas, dan gerakan sosial menentukan ciri-ciri politik modern dan masyarakat modern. Objek kajian dalam tulisan ini difokuskan pada gerakan Islam kontemporer seperti FPI serta himpunan organisasi lainnya yang tergabung dalam GNPF-MUI, sebuah gerakan kolektif yang mampu mendorong ribuan

\footnotetext{
Penulis mengkategorikan Front Pembela Islam (FPI) sebagai bagian dari gerakan politik Islam dengan dasar pertimbangan, Pada tabligh akbar FPI tahun 2002, disepakati oleh seluruh elit bahwa FPI memiliki sikap untuk menuntut Syariat Islam dimasukkan pada pasal 29 UUD 1945 dengan menambahkan "kewajiban menjalankan Syariat Islam bagi pemeluk-pemeluknya”. (Wahid, 2000, 44). Dengan adanya keikutsertaan ideologis FPI dalam bongkar pasang tata kenegaraan, terlebih lagi pengarus utamaan Islam sebagai sendi negara dan ada nyata secara legal formal, penulis mengkategorikan FPI sebagai salah satu representasi gerakan Islam Politik di Indonesia.
}

massa untuk berkumpul dan menyuarakan aspirasinya, yang dikaji secara periodik mulai pertengahan 2016 hingga aksi terakhir pada 2 Desember 2016.

Selain itu, terdapat konsepsi menarik dari Sztompka (1993:338) tentang gerakan sosial itu sendiri. Menurutnya, semua gerakan sosial berasal dari kondisi historis khusus. Gerakan sosial lahir dalam kecenderungan historis. Secara umum dapat dikatakan bahwa sebelum adanya struktur, sudah tersedia tumpukan sumber daya dan fasilitas untuk gerakan. Gagasan yang sudah ada sebelumnya biasanya digunakan untuk membentuk keyakinan, ideologi, penentuan tujuan, pengenalan kawan dan lawan, dan visi masa depannya. Paparan tersebut pada prosesnya kemudian akan penulis triangulasikan pada bagian pembahasan.

Terdapat banyak penelitian yang mengkaji tentang dinamika gerakan sosial politik terlebih gerakan keIslaman di Indonesia. Namun sejauh yang penulis ketahui, ada bebe-rapa tulisan penting yang cukup membantu penulis membangun kerangka teoritik. Seperti halnya tulisan Roy Murtadho dalamjurnal Indoprogress berjudul "Agama Dunia: Kritik terhadap Tafsir Agama Anti Massa-Rakyat" yang dengan rinci mengklasifikasi bentuk perjuangan Islam dari sudut pandang teologis juga perspektif gerakan. Penegasan terminologi Islam Politik juga penulis peroleh dari pengamatan artikel tersebut. Selanjutnya ialah penelitian Solahudin yangkemudian dibukukan berjudul"NII sampai JI: Salafy Jihadisme di Indonesia", cukup membantu pada konstruksi data, khususnya terkait runutan sejarah perjuangan negarawan Islamis dalam penanaman ideologi Islam pada landasan bernegara, serta tinjauan ringkas tentang Negara Islam Indonesia (NII). Dan terakhir ialah tulisan dari penulis sendiri yang berjudul "Puritanisme dan Fundamentalisme dalam Islam Transnasional serta Implikasinya terhadap Ketahanan Nasional", yang banyak memberikan referensi terkait pemetaan kekuatan radikal Islam di Indonesia.

\section{METODE}

Metode penelitian yang dipakai dalam menyusun tulisan ini layaknya seperti metode yang selalu dipakai dalam penelitian kualitatif, studi kualitatif dilakukan dengan mengumpulkan berbagai sumber baik sumber primer 
yaitu literatur utama dari yang dijadikan sumber, maupun sumber sekunder yaitu sumber-sumber penyokong seperti review terhadap sumber utama.

Dalam penelitian kali ini penulis menggunakan studi dokumentasi ataupun studi sejarah dalam menelaah fakta-fakta yang kemudian berkesinambungan dengan faktafakta kontemporer. Terlebih sebelumnya penelitian yang dikaji ini belum terlalu banyak dibahas sehingga perlu adanya penghimpunan data yang cukup agar validitas fakta sejarah dapat tercapai. Pada akhirnya studi doku-mentasi ini menghantarkan penulis kepada suatu pemikiran yang rasional dan argumentatif dalam memilah fakta dan konsep yang menampakkan dirinya.

\section{HASIL DAN PEMBAHASAN}

\section{Awal Pergerakan Reformis Islamisme di Indonesia}

Ide tentang nusantara berselimutkan panji Islam dapat ditelisik pertama kali pada masa kejayaan Sarikat Islam. Sarikat Islam -yang kemudian membentuk Partai dan berganti nama menjadi PSI- sejak awal menegaskan untuk "menuntut akan berlakunya syari'at Islam, di dalam arti kata yang seluas-luas dan sesempurna-sempurnanya, menurut contoh dan teladan yang nyata di dalam Sunnah Rasullullah" (Kartosoewirjo, 1999: 424). PSI sendiri tidak hanya hendak menegakkan khilafah Islamiyah di bumi Nusantara, tapi juga hendak menyebarkan pan-Islamisme ${ }^{2}$. Namun kemudian euphoria tersebut meredup akibat kurangnya perhatian dari negeri-negeri Islam lainnya (Noer, 1996: 153) ditambah PSI sendiri banyak dihantam oleh konflik internal yang terlalu banyak memusingkan arah kebijakan partai ke depan dengan bumbu sikut-sikutan yang tak berkesudahan pasca meninggalnya Tjokroaminoto pada tahun 1934.

Konsep negara Islam sebagai refleksi cita-cita gerakan Islamisme tak usai sampai disitu. Karena penerus-penerus ide tersebut terus bermunculan seiring perkembangan

${ }^{2}$ Pan Islamisme adalah gagasan untuk menyatukan umat Islam sedunia dalam satu sistem kekhalifahan (Solahudin, 2011: 58). Pan Islamisme pada hakikatnya memiliki kesamaan common enemy dengan dengan kaum sosialis komunis. Tan Malaka dalam komintern (forum Komunis Internasional) sebagai delegasi PKI bahkan menggelontorkan ide penggabungan atau kerjasama antara komunisme dengan pan-islamisme untuk melawan imperialis-kapitalis. Sayang ide tersebut tidak digubris oleh jajaran elit komintern dalam kongres komintern yang ke 4 di Moskow, dengan pertimbangan lemahnya urgensitas kerjasama tersebut (lihat pidato Tan Malaka dalam Kongres Komintern di Seri Buku Tempo: Tan Malaka, Bapak Republik yang dilupakan. Hlm. 76 iklim keislaman di Indonesia. Salah satu tokoh negarawan yang paling vokal menyuarakan Negara Islam ialah Mohammad Natsir. Natsir pernah berpendapat

"..memang Rasulullah tidak perlu menyuruh mendirikan negara. Akan tetapi dengan atau tanpa Islam, negara bisa berdiri, dan memang sudah berdiri sebelum dan sesudah Islam.. di zaman unta dan pohon korma sudah ada negara; zaman kapal terbang juga ada negara, dengan maupun tidak dengan Islam. Namun Islam datang membawa beberapa aturan tertentu untuk mengatur negara, supaya negara itu menjadi kuat dan subur, dan boleh menjadi wasilah yang sebaik-baiknya untuk mencapai tujuan hidup manusia yang berhimpun dalam negara itu, untuk keselamatan diri dan masyarakat, untuk kesentosaan perseorangan dan umum" (Natsir, 2014: 27).

Landasan argumen tersebut lah yang menjadi jawaban Natsir sebagai representasi kaum Islamis, kala menjawab kritikan Soekarno dalam buku "Islam Sontoloyo" nya, yang bersikukuh mengkritik khilafah dengan dasar argumen keruntuhan kekaisaran Ottoman, Turki.

Pertarungan perdebatan tersebut bahkan berlanjut dalam perdebatan perumusan asas negara. Melalui siding BPUPKI, Juni 1945, beberapa tokoh Islam modernis yang berasal dari Muhammadiyah dan wakil fraksi Islam lainnya seperti Ki Bagus Hadikusuma, Agus Salim, dan Abdul Kahar Muzakir, berhasil mendesak terciptanya Piagam Jakarta yang menegaskan asas negara berdasarkan "Ketuhanan, dengan kewajiban menjalankan syari'at Islam bagi pemeluk-pemeluknya". Dasar pertimbangan Ki Bagus Hadikusuma ialah berdasarkan apa yang ia paparkan dalam sidang BPUPKI ialah sebagai berikut:

"dalam negara kita, niscaya tuan-tuan menginginkan berdirinya satu pemerintahan yang adil dan bijaksana berdasarkan budi pekerti yang luhur, bersendi permusyawaratan dan keputusan rapat serta luas dan lapang dada, tidak memaksa tentang agama. Jika tuantuan benar benar menginginkan keadilan, kerakyatan, dan toleransi, maka dirikanlah pemerintah ini atas dasar Islam, karena Islam mengajarkan masalah tersebut" (Syaifullah, 1997: 107)

Usia Piagam Jakarta berlangsung singkat, karena sehari setelah kemerdekaan, 
kelompok Kristen dan Katholik mengancam akan mendirikan negara sendiri di Indonesia bagian timur. Setelah beberapa pertimbangan, ditambah bujukan dari Kasman Singodimedjo terhadap Ki Bagus Hadikusuma bahwa situasi tengah genting dan masyarakat perlu bersatu, perdebatan usai (Solahudin, 2011: 57) dan Pancasila sebagai representase legalitas sekuler resmi ditetapkan.

Perjuangan terbangunnya negara Islam yang khaffah bahkan terus berlanjut. Penulis membagi perjuangan Islamisme di Indonesia ke dalam dua arus. Arus pertama ialah arus moderat seperti apa yang diperjuangkan oleh Natsir. Dengan memanfaatkan partainya yakni Masyumi, ditambah dengan jabatannya sebagai perdana menteri, Natsir banyak menyuarakan ide-ide Negara Islam dalam berbagai media legal seperti perdebatan terbuka dalam kampanye menjelang pemilu 1955, hingga sidang Majelis Konstituante. Sayang, perjuangan Natsir usai setelah dirinya (beserta tokoh Masyumi lain seperti Mohammad Roem) terseret kasus makar melalui pemberontakan PRRI/Permesta.

Proses yang kedua ialah arus radikal. Aktor dari arus gerakan ini tidak lain dan tidak bukan ialah Kartosoewirjo dengan DI/TII sebagai kendaraannya. Jenuhnya Kartosoewirjo terhadap rekan indekosnya di masa lampau, Soekarno, akibat kebijakannya yang terlalu kooperatif dengan "kaum kafirin" Belanda, mengakibatkan Kartosoewirjo bersikukuh memproklamirkan Negara Islam Indonesia (NII) di Cilugagar, Tasikmalaya, pada 7 Agustus 1949 (Horikoshi, 1975: 59). Berbeda dengan Natsir dan kolega yang memperjuangkan Negara Islam tanpa konsep yang matang dan mendetail. Kartosoewirjo bahkan lebih dulu merumuskan regulasi mendetail tentang hukum Islam serta tata perundang-undangannya.

Holk Dengel (dalam Solahudin, 2011: 6667), menjelaskan secara rinci aturan Darul Islam. Secara ringkas dala Undang-undang hukum Pidana Negara Islam Indonesia (UUHPNII). Di pasal awal, dijelaskan tentang empat musuh yang ditetapkan rakyat dan pemerintah NII, pertama, orang bughot, yaitu orang-orang yang tidak tunduk kepada hukum pemerintah NII, kedua, orang munafik, adalah orang-orang yang sudah diberi penjelasan soal NII namun ia punya dua sikap pro NII juga pro RI. Hukuman untuk kaum munafik adalah hukuman mati. Ketiga, orang-orang fasik, yakni orang yang mengerti hukum Islam tapi tak menjalankannya. Hukuman mereka ialah bertobat, dan jika tetap menolak, akan ditetapkan sebagai musuh Islam yang boleh diperangi. Dan terakhir, orang yang membantu musuh. Hukumannya ialah ditetapkan sebagai musuh negara dan dihukum mati. UU diatas juga mengatur tentang berbagai perbuatan kriminal dan hukumannya seperti membunuh, berzina, minum minuman keras, mencuri ${ }^{3}$, membegal, termasuk murtad dan meninggalkan shalat.

Dan untuk melaksanakan UUHPNII, Darul Islam telah membagi wilayah Indonesia menjadi tiga wilayah, yaitu: Daerah I (D.I), daerah II (D.II) dan daerah III (D.III). Daerah I adalah daerah yang mana berlaku "kekuasaan dan hukum-hukum agama Islam.”. di daerah ini, UU Pidana NII dilaksanakan secara menyeluruh. Daerah ini juga bisa dikatakan sebagai basis Jihad gerakan NII. Untuk mendukung jihad, rakyat wajib mengikuti wajib militer (wamil). Kaum lelaki berusia 16-24 tahun wajib mengikuti wamil dan ketika selelsai mereka dikembalikan ke desa asalnya untuk menjadi pelopor DI. Warga juga harus menyerahkan $2.5 \%$ dari pendapatannya kepada NII. Sementara D.II adalah daerah yang setengahnya dikuasai NII, setengahnya lagi dikuasai musuh. Para kader disini harus melakukan pemberontakan dalam rangka mengubah D.II menjadi D.I. sementara D.III adalah daerah yang dikuasai musuh. Para pimpinan NII di sana memiliki tugas menarik simpati semua penduduk setempat, dan harus berupaya agar daerah ini menjadi D.II.

DI/TII sendiri pada akhirnya berhasil ditumpas melalui operasi pagar betis yang dikomandoi Ibrahim Adjie. DI/TII berhasil ditumpas karena ketiadaan simpati masyarakat akibat tindak tanduk perampokan, pemaksaan, dan pembunuhan yang dilakukan serdaduserdadu TII. Ketiadaan pemasukan logistik dan dana disertai ketiadaan dukungan dari pihak yang lebih kuat pengaruhnya, mengakibatkan Kartosoewirjo berhasil diciduk pada tahun 1962. Ketidakkonsistenan TII beserta para elitnya dalam menjalankan jihad lah kemudian yang membuat mereka semua menggali kuburannya sendiri. Ditumpasnya DI/TII dan ditangkapnya

\footnotetext{
3 Dalam kasus pencurian, siapa yang mencuri $1 / 4$ dinnar dari tempat penyimpanan yang baik untuk pertama kalinya dipotong tangannya sebelah kanan dari pergelangan. Kalau mencuri lagi untuk kedua kalinya dipotong kaki sebelah kiri, kalau mencuri untuk ketiga kalinya dipotong tangan kirinya, kalau mencuri keempat kalinya dipotong kaki kanannya. Dan bila mencuri lagi dibuang ke tempat yang paling dekat 1 qashar (16 pos) perjalanan. (Solahudin, 2011: 66)
} 
Natsir (walau kemudian dibebaskan kembali saat Soekarno jatuh) menandakan tamatnya perjuangan para tokoh dalam memperjuangkan Negara Indonesia berasaskan panji Islam secara terbuka.

\section{Transformasi Islamisme menuju Sebuah Gerakan Baru}

Gerakan Islam merupakan gerakan keagamaan yang muncul dari pergeseran orientasi keberagamaan dan ketidak puasan terhadap organisasi-organisasi ekstra kampus yang menyuguhkan kegiatan sekuler dan juga terhadap dua organisasi besar yaitu Nahdlatul Ulama(NU) danMuhammadiyah yang dianggap tidak concern mengubah masyarakat menjadi Islami (Edy, 1993: 12). Bisa jadi hal tersebutlah yang menguatkan Dewan Dakwah Islam Indonesia bentukan Mohammad Natsir merebut banyak hati mahasiswa dan bertransformasi menjadi lembaga alternatif dalam membentuk masyarakat yang Islami.

Setelah sekian lama dibungkam oleh rezim Orde Baru, gerakan Islamisme mulai menampakkan taringnya kembali pasca bergulirnya era reformasi. Konsolidasi Natsir pasca pembungkamannya oleh rezim Soeharto ditambah dengan kekecewaan Natsir terhadap pasifnya ormas mainstream seperti NU dan Muhammadiyah dalam menjalankan Islamisme, mendorong Natsir untuk membangkitkan Dewan Dakwah Islam Indonesia (DDII), yang pada prosesnya kemudian menginisiasi organisasi kemahasiswaan muslim terpandang bernama KAMMI, berhasil membangun Partai bernama Partai Keadilan (cikal bakal PKS di kemudian hari). Selain DDII dan KAMMI yang berhasil membangun massa di bidang akademik dan masjid-mesjid kampus, terdapat satu organisasi lainnya yang diam-diam mampu menancapkan pengaruhnya di jalur yang sama dengan DDII bentukan M. Natsir. Organisasi tersebut ialah Hizbut Tahrir Indonesia (HTI), organisasi Islam Transnasional yang menekankan Kekhalifahan Islam sebagai harga mati. HTI juga merupakan representasi Panislamisme kontemporer mengingat visi misinya lantang berbicara kebangkitan Islam mulai dari Afrika Barat hingga ujung timur Asia.

Pasca tumbangnya rezim Orde Baru, geliat gerakan keislaman semakin mengemuka, KAMMI -sebagai representasi Tarbiyyah kontemporer- bahkan ikut menginisiasi tum- bangnya Soeharto dari kursi presiden. HTI pun semakin terang-terangan meneriakkan Islam kaffah sebagai sistem formal. Diluar itu, pendirian organisasi masyarakat khususnya yang berhaluan Islam juga deras mengalir, salah satunya ialah Front Pembela Islam (FPI) yang berdiri 4 bulan setelah tumbangnya Soeharto. HTI dan FPI merupakan dua lembaga yang sangat aktif menghendaki penetapan Syariat Islam sepenuhnya dalam tatanan hukum dan sistem pemerintahan Indonesia. Pada tabligh akbar FPI tahun 2002, bahkan disepakati oleh seluruh elit agar FPI memiliki sikap untuk menuntut Syariat Islam dimasukkan pada pasal 29 UUD 1945 dengan menambahkan "kewajiban menjalankan Syariat Islam bagi pemeluk-pemeluknya". Sejalan dengan FPI, HTI juga semakin aktif menyebarkan selebaranselebaran tentang pentingnya Kilafah Islam, busuknya kapitalisme, dan Mudharat nya Pancasila. Beda hal dengan PKS yang menjalankan strategi moderat, dengan ikut berkompetisi pada pemilihan umum langsung dan mendukung serta mengakui pemerintahan Nasionalis. Secara parsial, kesemuanya memegang peranan penting dalam membangun pondasi gerakan Islam baru di era reformasi.

Meminjam istilah dari Abdurrahman Wahid, Kelompok Islam tersebut mengklaim sebagai pewaris tunggal kebenaran dan karenanya muslim yang berbeda dianggap kurang Islami atau bahkan kafir. Seperti pendahulunya, yakni DDII, kelompok ini gencar melakukan infiltrasi ke dalam lembaga pendidikan, instansi pemerintah, masjid, maupun ormasormas Islam, tak terkecuali Muhammadiyah dan Nahdhatul Ulama (NU). Hingga akhirnya, Muhammadiyah menerbitkan SK PP Muhammadiyah Nomor 149/Kep/I.0/B/2006 yang berisi tentang penolakan terhadap infiltrasi tersebut, pun halnya dengan NU melalui forum Bahtsul Masa'il nya (Wahid, 2000: 44). Pembahasan mengenai klaim pembenaran ini akan dibahas pada bagian selanjutnya.

Upaya tersebut bisa saja menekan gerakan di luar NU dan Muhammadiyah untuk berinfiltrasi dalam ranah internal. Namun kemudian, hegemoni NU dan Muhammadiyah saja nyata-nyatanya belum cukup menghimpun umat untuk satu konsesus dan bersepakat dalam satu suara apalagi gerakan. Adanya polarisasi pembiaran dan sifat tidak memaksa dalam proses kaderisasi kedua organisasi tersebut, 
pada prosesnya kemudian melahirkan kekuatankekuatan baru yang lebih "jujur" dan percaya diri untuk merefleksikan dirinya untuk turut serta dalam politik praktis. Tidak lah aneh jika kemudian, muncul kekuatan-kekuatan baru, baik melalui gerakan tarbiyyah yang membentuk partai resmi yang solid, maupun organisasi kemasyarakatan dengan corak tersendiri (baik dalam pemurnian agama maupun dalam ranah aktif politis). Titik balik dari seluruh gerakan antithesis NU dan Muhammadiyah tersebut ialah peristiwa kasus dugaan penistaan agama, dimana efek domino dari peristiwa tersebut ialah terbentuknya Gerakan Nasional Pengawal Fatwa MUI (GNPF-MUI).

Gerakan sosial biasanya didefinisikan sebagai seperangkat keyakinan dan tindakan yang tak terlembaga (noninstitutionalised) yang dilakukan oleh sekelompok orang untuk memajukan atau menghalangi perubahan di dalam sebuah masyarakat. Adapun yang dimaksud tak terlembaga adalah bahwa mereka tidak diakui sebagai sesuatu yang berlaku dan diterima umum secara luas dan sah di dalam sebuah masyarakat. Tetapi, bagi pengikut dan pendukung gerakan sosial tersebut, keyakinan dan praktek-praktek yang mereka lakukan didefinisikan secara positif (Mirsel, 2004: 7). Hal ini lah yang kemudian paling tepat menggambarkan bagaimana Gerakan Nasional Pengawal Fatwa MUI (GNPFMUI) terbentuk sebagai sebuah gerakan. Dengan adanya seperangkat keyakinan bahwa Gubernur DKI Jakarta Basuki Tjahaja Purnama bersalah dalam kasus dugaan penistaan agama, ditambah dengan keyakinan bahwa tindakannya merupakan jihad membela kitab suci Al-Quran, GNPFMUI kemudian menjelma menjadi sebuah gerakan representasi Islam kontemporer diluar NU dan Muhammadiyah, yang paling menonjol diantara gerakan-gerakan lainnya yang acapkali muncul mengatasnamakan Islam jua.

\section{Gerakan Islamisme Kontemporer: Fenomena Siklikal?}

Berdasarkan apa yang dikemukakan oleh Karl Mannheim, "A state of mind is utopian when it is incongruous with the state of reality within which it occurs... only those orientations transcending reality will be referred to by us as utopian which, when they pass over into conduct, tend to shatter, either partially or wholly, the order of things prevailing at the time" (Mannheim, 1991: 52). Mannheim pada dasarnya hendak menekankan bahwa realita (atau realitas) merupakan kunci untuk mengidentifikasi pemikiran dan keya-kinan seseorang serta kelompok tertentu, apa layak atau tidak disebut sebagai utopis. Ditengah krisis ekonomi, sosial, bahkan poli-tik yang menurut komunitas Islam tertentu diakibatkan oleh sekulerisme yang akut, pada akhirnya menyebabkan komunitas Islam tertentu (meminjam istilah Syamsul Arifin) mengembalikan segala sesuatu terhadap agama. Agama menjadi sebuah antithesis yang mampu mengalahkan segala yang dianggap "musuh". Pada akhirnya, kondisi di kemudian hari memberikan motivasi khusus pada tema-tema "Jihad". Akan lebih sempurna jika terdapat common enemy yang berwujud.

Dan dewasa ini, kita bisa menyaksikan betapa kasus penistaan agama yang diduga dilakukan oleh Gubernur DKI Jakarta, Basuki Tjahaja Purnama, cukup menyita perhatian media nasional bahkan dunia. Ada nya dugaan kasus penistaan terhadap salah satu surat AlQuran, yakni Al-Maidah ayat 51 tak ayal memancing beberapa ormas Islam "keluar dari sarangnya". Dan mendekati momentum pilkada DKI, kasus ini semakin menguat, terlebih saat terjadinya aksi massa yang berulang hampir selama empat gelombang. Hampir dari kesemuanya diinisiasi oleh ormas Islam bernama Front Pembela Islam (FPI) Pimpinan Rizieq Shihab. Yang kemudian membentuk sebuah gerakan bernama GNPFMUI.

Aksi 411 dan 212 pada hakikatnya merupakan momentum yang sangat tepat untuk FPI (dan juga GNPFMUI) perihal upayanya dalam mencuri panggung dalam hingar bingar politik dewasa ini. Tidak berlebihan pula jika FPI beserta mubaligh-mubaligh pendukungnya, kini menjelma menjadi representasi gerakan Islam kontemporer yang paling berpengaruh. Sejatinya, tampuk harapan gerakan Islamisme tertuju pada Partai Keadilan Sejahtera (PKS) pasca rezim Orde Baru runtuh. Langkah politiknya yang moderat, kaderisasi yang mapan mulai dari halaqah (pengajian kecil), organisasi kemahasiswaan (KAMMI), hingga soliditas elit partai, mengakibatkan PKS sebagai agen representatif tarbiyah internasional, cukup menyita perhatian pemilih politik di Indonesia, diikuti partai-partai politik sokongan ormas besar seperti PAN, PKB, dan PPP yang lebih 
dulu bergerilya sejak tahun 1999. Adanya tindak pidana, perdata, dan perkara amoral yang dilakukan oknum elit partai lah yang kemudian mengendurkan suara PKS hingga detik ini. Sehingga wajar, jika vacuum of power dalam perwakilan kekuatan Islam, kemudian diisi oleh FPI dibawah kendali Rizieq Shihab.

Kasus penistaan agama menurut hemat penulis merupakan fenomena gunung es, karena dibalik semua itu, terdapat kekecewaankekecewaan tersendiri mulai dari perdebatan ideologis mengenai Pancasila yang dinilai kurang solutif, kekalahan calon tertentu dalam pilpres 2014, hingga luapan aspirasi pihak-pihak loser yang terkorbankan akibat dikeluarkannya produk politik tertentu dalam bentuk kebijakan, baik di tingkat nasional maupun regional. Dan dalam perspektif budaya, juga terdapat endapan sentimen anti ras tertentu yang akhirnya meledak setelah dipantik suatu kasus yang berkaitan dengan hal sensitif, yakni agama.

Dan fenomena siklikal (terulang) pun hampir bisa dibilang terjadi. Kebangkitan gerakan Islam post-reformasi yang muncul akibat kekecewaan terhadap kaum nasionalissekuler, dewasa ini juga mengalami pengulangan serupa. Bedanya, jika pada masa post-reformasi, gerakan Islamisme terpecah menjadi dua arus. Kini gerakan Islamisme menunjukkan soliditasnya. Hal ini terlihat dari bagaimana elemen-elemen Islam dari berbagai aliran bersatu dalam sebuah aksi. Islam transnasional yang diwakili Hizbut Tahrir dan gerakan Tarbiyah PKS, dalam peristiwa 411 atau 212 duduk bersama bahkan menjalankan ibadah bersama. Hal ini jelas memperlihatkan progress bagi gerakan Islamisme.

Hanya saja, ada fenomena lain yang kemudian terulang pada grassroot. Generasi milenial pengguna sosial media merupakan tersangka utama dalam pengulangan fenomena yang terakhir. Jika dulu, elit dan serdadu serta simpatisan NII mudah mengkafirkan pihak lain (yang bahkan diatur dalam Undang-undang internal NII), fenomena tersebut kini telah terjadi kembali. Adanya kasus dugaan penistaan agama kemudian memecah massa kepada dua kutub berlawanan. Pihak pertama menurut hemat penulis ialah alumnus aksi 212 beserta para simpatisannya yang menilai Gubernur DKI Ahok bersalah diikuti oknum-oknumnya yang menganggap pembela Ahok adalah kafir. Dan pihak kedua ialah para pembela Ahok yang menilai para simpatisan dan oknumnya menghadirkan situasi intoleran dan menyalahi Pancasila. Beberapa peristiwa pun kemudian bermunculan, mulai dari penganiayaan wartawan dari agama tertentu (atas dasar KTP yang dipaksa untuk diperlihatkan), sampai keengganan takmir masjid tertentu di Jakarta untuk mengurus jenazah muslim yang memilih Ahok pada Pilkada DKI 2017. Khusus untuk perkara tersebut, hal tersebut jelas mencederai konsensus Pancasila yang telah disepakati dan tengah berproses dalam penegakan masyarakat bertuhan, beradab, bersatu, bermusyawarah, dan adil secara sosial.

Pada akhirnya, ilusi dan utopia mengenai ketuhanan yang semu, dan hanya diadopsi dari pengamatan kulit luar dana bunya saja (seperti apa yang dikatakan Soekarno dalam "Islam Sontoloyo") secara tak langsung (kembali) mengulang apa yang gerakan Islamisme sebelumnya lakukan, yakni menggali kuburannya sendiri. Tanpa adanya keterbukaan dalam perspektif dialektis, sampai kapanpun gerakan Islamisme di Indonesia tidak akan bergerak kemana-mana. Bahkan kemudian akan tenggelam di titik lama. Titik dimana gerakan Islamisme pernah berjaya dalam putaran lingkaran sektoral yang itu-itu saja.

\section{SIMPULAN}

Pada hakikatnya, transformasi bentuk perjuangan Islamisme dari yang sebelumnya berwujud gerakan kemasyarakatan yang agitatif dan propagandis pada masa pra dan pasca kemerdekaan, kemudian menjadi gerakan kajian keagamaan yang pasif, hingga kemudian kembali menjadi sebuah gerakan kemasyarakatan yang aktif memperjuangkan Islamisme sebagai refleksi modernitas masyarakat dewasa ini telah menunjukkan progress maksimal bagi Islamisme itu sendiri. Islamisme dalam bentuk gerakan juga pada akhirnya merestui persatuan umat Islam dari berbagai mahzab mulai dari Islam tradisionalis hingga Islam Transnasionalis dalam satu ruang dan wadah yang sama walaupun prosesnya masih harus menunggu munculnya common enemy dan menumbalkan Ahok sebagai target sasaran sekaligus pemersatu.

Namun perlu diingat, konsep Islamisme yang terrefleksi menjadi sebuah gerakan, sampai kapanpun akan menjadi sebuah gerakan utopis jika sinkronisasi antara para penggerak gerakan 
(yang dewasa ini diinisiasi sejumlah mubaligh dan beberapa ulama) dan umat di jajaran grassroot tidak berjalan sinergis. Konsep negara Islam yang hendak didamba pun kelak akan habis menjadi abu jika pondasi dialektis dan filosofis nya tidak kuat sama sekali. Mengingat saat ini, Pancasila, ditinjau dari perspektif apapun bagi penulis merupakan konsep filsafati komprehensif yang telah mencakup seluruh aspek yang dibutuhkan bangsa Indonesia mulai dari toleransi, persatuan, musyawarah, hingga keadilan sosial yang menjadi cita-cita bangsa di masa depan. Selagi para elit gerakan Islamis masih meributkan ghirah atau hal-hal perkara kulit luar, bahkan sampai diam apalagi mendukung tindak intoleran seperti tindakan rasial dan lain sebagainya, mimpi untuk membangun Indonesia yang berkepribadian Islam dan taat tegak terhadap hukum Islam sampai kapanpun akan menjadi angan-angan karena yang terjadi kemudian adalah konflik horizontal yang berkepanjangan.

\section{DAFTAR PUSTAKA}

Abdullah, Anzar. (2016). Gerakan Radikalisme Dalam Islam: Perspektif Historis. Jurnal ADDIN. 10(1). 1-28.

Arifin, Syamsul. \& Hasnan Bachtiar. (2013). Deradikalisasi Ideologi Gerakan Islam Transnasional Radikal. Jurnal Multikultural \& Multireligius. 12(3). 19-36.

Bachtiar, Anis. (2013). Orientasi Ideologis Gerakan Modern Islam: Kajian Historis Awal Abad 20. Jurnal Tribakti 15(2). 181-194.

Edy A, Efendi (1993). Pergeseran Orientasi Sikap Keberagamaan di Kampus-Kampus Sekuler. Ulumul Qur'an. 4(3). 12-34.

Fealy, Greg dan Anthony Bubalo. (2007). Jejak Kafilah: Pengaruh Radikalisme Timur Tengah di Indonesia. Bandung: Mizan.

Fealy, Greg, Anthony Bubalo dan Whit Mason. (2012). PKS dan Kembarannya: Bergiat jadi Demokrat di Indonesia, Mesir, dan Turki. Jakarta: Komunitas Bambu.

Engineer, Asghar Ali. (2009). Islam dan Teologi Pembebasan. Yogyakarta: Pustaka Pelajar.
Hiariej, Eric. (2010). Aksi dan Identitas Kolektif Gerakan Islam Radikal di Indonesia. Jurnal Sosial Politik. 14(2). 131-168.

Horikoshi, Hiroko. (1975). The Darul Islam Movement in West Java (1948-62): An Experience in Historical Process. Jurnal Indonesia: Cornel Modern Indonesia Project, 59-86.

Kartosoewirjo. S.M. (1999). Al-Chaidar, Pemikiran Politik Proklamator Negara Islam Indonesia S.M. Kartosoewirjo. Jakarta: Darul Falah.

M. Nuh. Nuhrison. (2009). Faktor Penyebab MunculnyaPaham/GerakanRadikalisme di Indonesia. Jurnal Multikultural \& Multireligius. 8(31). 35-47.

Mahmuddin. (2015). Formalisme Agama dalam Perspektif Gerakan Sosial: Prospek dan Tantangan di Masa Depan. Jurnal Diskursus Islam. 3(1). 37-48.

Mannheim, Karl. (1991). Ideology and Utopia. London: Routledge.

Mirsel, Robert. (2004). Teori Pergerakan Sosial. Yogyakarta: Resistbook.

Murtadho, Roy. (2016). Agama Dunia: Kritik terhadap Tafsir Agama Anti MassaRakyat. Diakses 27 Februari 2017, dari: http://www.indoprogress.com/2016/10/ agama-dunia-kritik-terhadap-tafsiragama-anti-massa-rakyat/

Natsir, Mohammad. (2014). Islam sebagai Dasar Negara. Bandung: Sega Arsy.

Noor, Deliar. (1992). Gerakan Modern Islam di Indonesia 1900-1942. Jakarta: LP3Es.

Nur Hakim, Rakhmat. (2014). Gerakan Islam Politik Fundamentalis: Kasus Hizbut Tahrir Indonesia di Surabaya. Jurnal Review Politik. 4(2). 207-231.

Saiffudin.(2011). RadikalismeIslam diKalangan Mahasiswa (Sebuah Metamorfosa Baru). Jurnal Analsis. 11(1). 17-32

Soekarno. (2015). Islam Sontoloyo. Bandung: Sega Arsy.

Syaifullah. (1997). Gerak Politik Muhammadiyah dalam Masyumi. Jakarta: Grafity Press. 
Syaikhu, Achmad. (2012). Pergulatan Organisasi Islam dalam Membendung Gerakan Ideologi Islam Transnasional. Jurnal Falasifa. 3(1). 115-133.

Tempo. (2010). Tan Malaka: Bapak Republik yang Dilupakan. Jakarta: Kepustakaan Populer Gramedia (KPG).

Tri Prasetyo, Bayu. (2012). Gerakan Islam Politik Ikhwanul Muslimin di Timur Tengah Pasca Keruntuhan Turki Utsmani. Jurnal Analisis Hubungan Internasional UNDIP. 1(1). 271-290.
Wahid, Abdurrahman. (2009). Ilusi Negara Islam: Ekspansi Gerakan Islam Transnasional di Indonesia. Jakarta: Gerakan Bhinneka Tunggal Ika-The Wahid Institute-The Maarif Institute.

Wasito. (2016). Gerakan Sosial Modern Masyarakat Islam di Indonesia. Jurnal Tribakti. 27(2). 248-266. 